\title{
A voz do beneficiário: uma análise da eficácia do Programa Bolsa Família
}

\author{
Michelle Costa Marques dos Santos \\ Universidade Federal do Amazonas \\ Antonio Gouveia Junior \\ Universidade Federal do Amazonas \\ Paulo Roberto Marques de Oliveira \\ Universidade Federal do Amazonas \\ Daniel Reis Armond de Melo \\ Universidade Federal do Amazonas \\ Waldemar Antonio da Rocha de Souza \\ Universidade Federal do Amazonas
}

\begin{abstract}
Esta pesquisa analisa a eficácia do Programa Bolsa Família (PBF), pela perspectiva dos beneficiários deste programa de transferência de renda. Para tanto, foi desenvolvida uma pesquisa quali-quantitativa com 50 beneficiários e seu resultado analisado pela metodologia do discurso do sujeito coletivo (DSC), desenvolvida por Lefèvre e Lefèvre (2003). Da análise dos discursos, foi constatado que o beneficiário percebe como resultado de sua inserção no PBF o aumento da renda e a melhoria da qualidade de vida da sua família. Contudo, observaram-se falhas na percepção de alguns objetivos do programa, principalmente relacionados com a emancipação sustentada das famílias.
\end{abstract}

Palavras-chave: Programa Bolsa Família; eficácia; análise.

La voz del beneficiario: un análisis de la eficacia del Programa Bolsa Família

Esta investigación analizar la eficacia del Programa Bolsa Familia (PBF), desde la perspectiva de los beneficiarios de este programa de transferencia de efectivo. Para esta, se desarrolló una investigación cualitativa-cuantitativa con 50 beneficiarios y su resultado se analizó por el método del discurso del sujeto colectivo (DSC), desarrollado por Lefèvre y Lefèvre (2003). Del análisis del discurso, se encontró que el beneficiario percibe como consecuencia de su inclusión en el PBF un aumento en el presupuesto y la mejora de la calidad de vida de su familia. Sin embargo, estudio también reveló algunas fallas

DOI: http://dx.doi.org/10.1590/0034-76121663

Artigo recebido em 27 jul. 2013 e aceito em 26 jun. 2014.

Rev. Adm. Pública - Rio de Janeiro 48(6):1381-1405, nov./dez. 2014 
en la percepción de los objetivos del programa, principalmente relacionados con la emancipación permanente de las familias.

Palabras clave: Programa Bolsa Família; eficácia; análisis.

The voice of the beneficiary: an analysis of the effectiveness of the Bolsa Família Program This research aims to analyze the effectiveness of the Bolsa Família Program (PBF), from the perspective of the beneficiaries of this cash transfer program. In order to do it, it was developed a qualitativequantitative research with 50 beneficiaries and the outcome was analyzed using the collective subject discourse (DSC) methodology, developed by Lefèvre and Lefèvre (2003). From the discourse's analysis, it was verified that the beneficiary perceives as a result of his inclusion in PBF an income increasing and improvements on their family's life quality. However, there were flaws regarding the perception of some objectives of the program, especially related to sustained emancipation of families.

Keywords: Bolsa Família Program; effectiveness; analysis.

\section{Introdução}

No cenário das políticas públicas brasileiras, os programas de transferências de renda ganharam relevância diante dos desafios do Estado social, tornando-se tópico recursivo na extensa literatura sobre políticas sociais. Nesse sentido, Silva e Jesus (2011) apontam que, principalmente nos países em desenvolvimento, há uma crescente preocupação com a avaliação das ações e políticas sociais, com o intuito de proporcionar subsídios para melhoria da eficácia dos programas e oferecer respostas sobre a efetividade social das políticas implantadas.

No Brasil, o Programa Bolsa Família (PBF) traduz-se no programa de maior alcance nacional na distribuição de renda do governo federal, atendendo atualmente mais de $13 \mathrm{mi}$ lhões de famílias em situação de pobreza e de extrema pobreza. Em 2003, 12\% dos brasileiros estavam na condição de pobreza extrema e, em 2008, esse percentual diminuiu para 4,8\%, de acordo com o Ministério do Desenvolvimento Social (MDS). Endossa ainda esses números o estudo do Ipea (2013), que aponta o aumento de 14\% na renda per capita domiciliar entre os 10\% mais pobres no período de 2011 a 2012.

No entanto, ainda não se pode registrar unanimidade nas pesquisas quanto à eficácia do PBF na redução dos problemas sociais no Brasil. Segundo Denubila, Ferreira e Monteiro (2010), ainda existem divergências de opiniões positivas e negativas a respeito da eficácia do referido Programa.

Particularmente Manaus (AM), segundo o MDS, é a sétima cidade do país com maior quantidade de habitantes, com cerca de 1.802.525 habitantes, e possui em torno de 128 mil famílias beneficiárias que recebem em média $\mathrm{R} \$ 144,51$ mensais por beneficiário (MDS, 2013). Essa renda ainda pode ser complementada pela Prefeitura, que criou em 2010 o Programa Bolsa Família Municipal Consorciada (PBFMC). De acordo com a Secretaria Municipal de Assistência Social e Direitos Humanos (Semasdh), até agosto de 2012, a Prefeitura já be- 
neficiava 56.493 famílias por mês, o que representava $64,64 \%$ do total atendido pelo PBF em Manaus (AM).

Logo, faz-se necessário investigar o resultado da aplicação desses recursos na qualidade de vida, educação, saúde e na possibilidade da emancipação dessas famílias, principalmente porque não foram identificadas pesquisas similares aplicadas no estado do Amazonas. Para Guerra e colaboradores (2012), é essencial examinar se os objetivos e as condicionalidades do PBF estão sendo cumpridos, considerando que, apenas em 2012, seus investimentos somaram mais de $\mathrm{R} \$ 16$ milhões.

Este trabalho tem por objetivo analisar a eficácia do PBF sob a ótica dos beneficiários de Manaus (AM). Especificamente, pretende-se apontar os objetivos do PBF, examinando-os conforme a percepção dos 50 beneficiários entrevistados, aplicando a ferramenta metodológica do discurso do sujeito coletivo (DSC) e interpretando seus resultados.

\section{Referencial teórico}

\subsection{Políticas sociais}

A conjuntura em que se desenvolvem as atividades estatais é crescente, dinâmica e volátil. A interação entre indivíduos e o Estado tem se intensificado como consequência da globalização dos mecanismos de controle social, exigindo a permanente evolução das estruturas organizacionais de fomento de políticas públicas sociais, traduzidas em programas de transferência de renda.

Segundo Castro e colaboradores (2009), a partir do século XX desenvolveram-se os sistemas de proteção social com vista a enfrentar a crise de desagregação da solidariedade encontrada nas sociedades modernas. Com efeito, usaram-se como instrumentos políticas públicas integradas revestidas de caráter inclusivo, principalmente voltadas aos sistemas de habitação, educação, assistência social e saúde.

Nessa direção, afirma Hofling (2001), que as políticas sociais são, em si, ações emanadas pelo Estado, que objetivam a determinação do padrão de proteção social aos indivíduos afetados pelo desequilíbrio material, advindo do desenvolvimento socioeconômico. Para a citada autora, esse conceito advém das consequências da revolução industrial, principalmente quanto aos conflitos próprios da relação capital-trabalho.

Nesse sentido, as políticas sociais surgiram como uma forma da dinâmica capitalista de se adequar às condições de reprodução da força de trabalho por meio do Estado intervencionista. Esse cenário incide em ações governamentais essencialmente compensatórias ou assistencialistas, que não têm o fito de e frequentemente não se propõem à modificação das relações estabelecidas na sociedade (Hofling, 2001).

Segundo Demo (2006), as políticas sociais e as assistenciais não se confundem, apesar de as últimas constituírem uma vertente das primeiras, uma vez que essas ações assistenciais geram apenas efeitos superficiais. A esse respeito, ao criticar as políticas meramente assisten- 
ciais, o autor assevera que as políticas sociais não podem se concentrar apenas em propostas de distribuição de benefícios materiais, especificamente, transferência de renda, mas devem se voltar, sobretudo, para a ampliação do acesso a direitos e mudanças estruturais na dinâmica produtiva.

Ainda referente às críticas ao modelo, Fonteles e colaboradores (2011) observam que a omissão da pobreza e a acomodação gerada pela certeza daquela renda mensal, desde que cumpram as condicionantes, podem interferir negativamente na mobilidade social dessas famílias.

Noutro ponto, Marsiglia, Silveira e Carneiro Junior (2005) ressaltam duas vertentes para o alcance das finalidades e funções da política social que envolve a distribuição de recursos. Um primeiro aspecto refere-se a políticas compensatórias, com o objetivo de garantir condições mínimas de subsistência àqueles indivíduos que perdem a capacidade de auferir renda satisfatória para o sustento familiar. A outra está atrelada às políticas de redução da pobreza, que, ao contrário das anteriores, têm caráter temporário, objetivando a integração dos indivíduos em situação de vulnerabilidade social a uma vida regular na sociedade, reduzindo ou eliminando as principais carências que colocam em risco sua sobrevivência.

Figueiró (2010) reconhece a necessidade da política social como instrumento de alívio imediato da pobreza. Porém, adverte que, ao contrário da noção de desigualdade social, mais especificamente o aspecto da pobreza, manifestada pela deficiente distribuição econômica, torna-se primordial que a política social atente-se às características subjetivas da exclusão social como a perda de identidade e dignidade do indivíduo, ou seja, a destituição das condições e direitos básicos para a satisfação de suas necessidades enquanto cidadão.

Sobre o termo cidadania, afirma Fleury (2003) que essa corresponde à autonomia de indivíduos inseridos em uma sociedade, por meio de instrumentos de socialização (escola, família, comunidade etc.), e que participam ativamente das instituições públicas pelo exercício de um conjunto de direitos e deveres. A esse conceito liga-se a noção de emancipação, como estágio do indivíduo que se norteia pelo reconhecimento do seu papel social, principalmente vinculado à possibilidade de acesso a educação e trabalho, como forma de torná-lo um indivíduo autônomo e participativo (Figueiró, 2010).

Considerando essas vertentes conceituais, Kerstenetzky (2009) ressalta que as políticas sociais voltadas aos programas de transferência de renda são instrumentos eficazes para o alcance desses objetivos desde que as ações governamentais tenham foco no atendimento das pessoas mais pobres, no acesso dessas aos serviços públicos básicos e na determinação das condicionalidades como forma de emancipação dos beneficiários e ampliação da cidadania.

\subsection{Programas de transferência de renda no Brasil}

Essencialmente, os programas de transferência de renda dividem-se em duas vertentes: renda básica de cidadania e renda mínima garantida. A primeira constitui-se na transferência universal de renda, pelo Estado, a todos os cidadãos, sem qualquer restrição de cunho social ou econômico. Já a renda mínima garantida distingue-se por direcionar a renda para as 
classes em situação de pobreza, bem como não exigir contribuições dos favorecidos (Castro et al., 2009).

Esta última modalidade tem apresentado uma variante singular em alguns países, normalmente quanto à exigência de condicionalidades a serem cumpridas pelos beneficiários, em regra associados ao acompanhamento escolar e ao acesso a programas de saúde, como exemplo, todos os programas de transferência de renda instituídos no Brasil.

Conforme Lavinas, Cobo e Veiga (2012), a partir da década de 1990, houve uma propagação de programas de transferência de renda na América Latina, primordialmente focados em benefícios assistencialistas para as classes mais pobres da população, que há muito tempo careciam de mecanismos de mitigação da miséria. Nesse âmbito, as citadas autoras ressaltam que a tradição filantrópica dos países da região restringiu por muitas décadas a consolidação de um sistema de proteção social baseado em benefícios não contributivos.

No Brasil, o fomento à estruturação de políticas públicas sociais surgiu inicialmente no Governo de Getúlio Vargas na década de 1930, porém sem a sistematização necessária para formação de uma agenda no longo prazo, pois as práticas clientelistas e eleitorais contaminavam os critérios para a implementação dos programas governamentais.

Apenas com o advento da Constituição Federal de 1988 surgiram inovações quanto a indicadores sociais e estruturas de financiamento para políticas sociais, como programas de transferência de renda voltados à erradicação da fome e da pobreza (Sá e Silva, 2012; Lindert et al., 2007). Nesse sentido, nos últimos anos, destacam-se os períodos dos governos de Fernando Henrique Cardoso e Luiz Inácio Lula da Silva como marcos do crescimento de políticas de transferência de renda no Brasil.

Inicialmente, na década de 1990 houve um rompante de fortalecimento na agenda das políticas sociais brasileiras com a aprovação do Projeto de Lei no 80/1991, o qual instituiu o Programa de Garantia de Renda Mínima (PGRM), destinado a cidadãos que recebessem rendimentos brutos mensais inferiores a Cr\$ 45.000,00 (quarenta e cinco mil cruzeiros). Já nos anos de 1994 a 2002, caracterizados pela reestruturação da estabilidade econômica, instituiu-se a descentralização dos programas de transferência de renda como os Programas Bolsa-Escola, Bolsa-Alimentação, Cartão-Alimentação e Auxílio-Gás, os quais eram baseados em condicionalidades não contributivas.

Esses programas foram unificados em 2003 no governo de Luiz Inácio Lula da Silva com a criação do Programa Bolsa Família, que ampliou a abrangência da transferência direta de renda às famílias em situação de vulnerabilidade social e contribui para a evolução dos mecanismos de controle e gestão de políticas públicas sociais de transferência de renda.

\subsection{Programa Bolsa Familia}

Criado em 2004 e regulamentado pelo Decreto nํ⒌209/2004, o Programa Bolsa Família (PBF) foi posteriormente integrado ao Plano Brasil Sem Miséria, definindo seu foco na 
transferência direta de renda com o intuito de favorecer famílias em situação de pobreza ou de extrema pobreza, baseado em garantia de renda, inclusão produtiva e acesso aos serviços públicos.

Segundo Guerra e colaboradores (2012), em termos gerais, o PBF é caracterizado como um subsídio à demanda, uma vez que é direcionado às famílias em situação de exclusão econômica, com o intuito de melhorar suas possibilidades de acesso aos serviços públicos de saúde, educação e assistência social. Além disso, ele tem como proposta o cumprimento de condicionalidades para as famílias, com o objetivo de ser um estímulo ao desenvolvimento de capital humano.

O PBF possui três eixos elementares: a transferência de renda, as condicionalidades, e as ações e programas complementares. Na transferência de renda o objetivo do Programa é aliviar imediatamente os encargos da pobreza. O eixo condicionalidades direciona o beneficiário aos direitos sociais básicos no que tange à educação, à saúde e à assistência social. Por fim, as ações e programas complementares têm por finalidade o desenvolvimento das famílias, de forma que os beneficiários consigam ultrapassar a situação de vulnerabilidade.

Nesse âmbito, o Ministério do Desenvolvimento Social e Combate à Fome (MDS) executa por meio do PBF cinco tipos de benefícios: benefício básico, concedido para famílias com renda per capita igual ou inferior a $\mathrm{R} \$ 70$ (setenta reais); benefício variável, concedido pela existência na família de crianças de zero a 15 anos, gestantes e/ou nutrizes; ou ainda, concedido pela existência na família de jovens entre 16 e 17 anos; benefício variável de caráter extraordinário, concedido para famílias migradas de programas remanescentes ao PBF; e benefício para superação da extrema pobreza na primeira infância, concedido para famílias com crianças entre zero e seis anos, que superem os $\mathrm{R} \$ 70,00$ (setenta reais) de renda mensal per capita.

Ressaltam Sá e Silva (2012) que, fora o repasse do valor monetário, o Programa Bolsa Família é essencial para ampliar outros programas, como alfabetização, capacitação profissional, apoio à agricultura familiar, geração de ocupação e renda, microcrédito, acesso à educação e serviços de saúde para os filhos. Dessa forma, o Programa também contribui para viabilizar a autonomia das famílias beneficiárias, assim como, segundo Rasella (2013), possibilitar uma notável redução da mortalidade infantil considerando as condicionantes impostas pelo Programa.

Para Figueiró (2010), o efetivo enfrentamento dos problemas sociais advém da integração de ações assistenciais temporárias e políticas que gerem mudanças estruturais, como educação, saúde e geração de renda. Para a citada autora, denotam-se, na concepção do PBF, ações imediatistas, como a transferência de renda e ações estruturais de inclusão social. De igual modo concluiu a pesquisa do Ibase (2008) quanto à necessidade de associação do Programa a outras políticas governamentais, capazes de enfrentar os problemas correlatos à pobreza e à insegurança alimentar, como as barreiras no acesso ao mercado formal de trabalho.

Consoante o destaque de Guerra e colaboradores (2012), outro fator importante no PBF, e que igualmente se faz presente na própria diretriz da Política Nacional de Assistência Social, é o atendimento ao núcleo familiar, e não a indivíduos isoladamente. Nessa direção, os 
objetivos básicos do Programa Bolsa Família em relação à família do beneficiário são: promover o acesso à rede de serviços públicos, em especial, de saúde, educação e assistência social; combater a fome e promover a segurança alimentar e nutricional; estimular a emancipação sustentada das famílias que vivem em situação de pobreza e extrema pobreza; combater a pobreza; e promover a intersetorialidade, a complementaridade e a sinergia das ações sociais do poder público.

E, para que esses objetivos sejam alcançados, foram traçadas as condicionalidades do PBF, conforme o MDS, centradas em três vertentes. No campo da saúde, as famílias beneficiárias acordam acompanhar o cartão de vacinação e o crescimento e desenvolvimento das crianças menores de sete anos. As mulheres com idades entre 14 e 44 anos também devem fazer o acompanhamento e, em caso de gestantes ou nutrizes, devem realizar o pré-natal e o acompanhamento da sua saúde e do recém-nascido. Do mesmo modo, na educação, todas as crianças e adolescentes entre seis e 15 anos devem estar matriculados e com frequência escolar mensal mínima de 85\%, bem como os estudantes entre 16 e 17 anos devem ter frequência mínima de 75\%. No âmbito da assistência social, crianças e adolescentes com até 15 anos em risco ou retiradas do trabalho infantil pelo Programa de Erradicação do Trabalho Infantil (Peti) devem participar dos Serviços de Convivência e Fortalecimento de Vínculos e obter frequência mínima de $85 \%$.

Segundo Mourão, Ferreira e Jesus (2012), a finalidade das condicionalidades é que as famílias devem adquirir responsabilidades para receberem os benefícios. Nesse sentido, a condicionalidade não tem caráter punitivo, mas, sim, propõe a ampliação do acesso aos direitos sociais básicos para os beneficiários, de forma que estes possam exercer a sua cidadania.

Importante observar ainda o caráter integrado do gerenciamento do Programa Bolsa Família, uma vez que sua gestão é descentralizada e compartilhada entre a União, estados, Distrito Federal e municípios, que devem cooperar em conjunto para aperfeiçoar, ampliar e fiscalizar a execução do Programa. Dessa forma, para monitorar o cumprimento dos objetivos do PBF, o Ministério de Desenvolvimento Social e Combate à Fome (MDS) utiliza como principal instrumento o Índice de Gestão Descentralizada (IGD). Segundo Estrella e Ribeiro (2008), o IGD monitora os registros e informações sobre as condicionalidades, e se fundamenta em dados da administração municipal.

Atualmente, o PBF atende a mais de 13 milhões de famílias em todo o país. Em Manaus, beneficia em torno de 128 mil famílias, com valor médio recebido de $\mathrm{R} \$ 144,51$ por beneficiário. Segundo o MDS, esse quantitativo representa uma cobertura de 99,5\% da estimativa de famílias pobres no município (MDS, 2013).

Dessa forma, em conformidade com o caráter cooperativo do Programa e com o objetivo de elevar o índice de desenvolvimento das famílias beneficiárias do PBF, foi instituído, por meio da Lei Municipal no 1.402, de 14 de janeiro de 2010, o Programa Bolsa Família Municipal Consorciada (PBFMC) para a transferência do valor de R\$ 60 (sessenta reais) mensais para as famílias registradas no Cadastro Único (CadÚnico), com renda per capita mensal de até $R \$ 70$ (setenta reais) e que tenham dependentes de até 15 anos, como complementação do benefício recebido pelo PBF, financiado pelo governo federal. 
Nesse contexto, nos últimos anos percebe-se um crescente aumento da quantidade de estudos sobre diversos aspectos do PBF. Em um ponto, recentes pesquisas de âmbito local tendem a concordar quanto ao impacto positivo do PBF nas famílias em situação de vulnerabilidade social, assim como apontam Rosinke e colaboradores (2011), ao constatarem que a transferência de renda pelo PBF contribui como propulsor de desenvolvimento das economias locais. No mesmo sentido, Traldi, Almeida e Ferrante (2012) concluíram que, apesar das fragilidades, o PBF assume um papel essencial na garantia inicial da segurança alimentar e do bem-estar das famílias assistidas.

Por fim, cabe evidenciar que alguns estudos divergem quanto à eficácia do Programa Bolsa Família, como Mendes, Barbosa e Rodrigues (2009), que concluíram que o PBF não tem exercido uma função emancipatória voltada à efetivação da cidadania, porém a maioria dessas pesquisas corrobora no sentido de que a transferência de renda, mesmo em pequeno valor monetário, resulta na transformação da capacidade de consumo das famílias atendidas, impactando por meio das condicionalidades os indicadores socioeconômicos de diminuição da desigualdade de renda (Denubila, Ferreira e Monteiro, 2010).

\subsection{Avaliação de políticas públicas}

Os Estados Unidos promoveram, na década de 1960, um grande avanço na avaliação de políticas e programas públicos, segundo Faria (2005), a qual foi institucionalizada pelo governo, determinando a avaliação dos programas sociais americanos. Com isso, outros países passaram a priorizar a aferição dos resultados a partir da década de 1990.

Faria (2005) apontou ainda que na América Latina a avaliação de políticas públicas se inseriu nas reformas estatais das décadas de 1980 e 1990. Essas reformas, de acordo com Melo (1998), apresentavam propósitos como conter gastos públicos, melhorar a eficiência e produtividade dos governos e promover a transparência da gestão pública, inclusive com a responsabilização de gestores. Silva e Jesus (2011) indicam ainda que, nos países em desenvolvimento, se observa uma crescente preocupação com a avaliação das ações e políticas sociais.

Sobre dimensões de desempenho na área pública, Torres (2004) esclarece que a eficácia representa o grau de alcance dos resultados pretendidos, sem considerar a razão de economicidade e viabilidade dos recursos e instrumentos dispendidos na ação estatal. De outra forma, essencialmente mais complexa, a efetividade corresponde à mensuração dos benefícios da ação estatal, considerando o binômio necessidade-oportunidade na decisão e implementação das políticas.

Para Melo (1999), as mudanças ocorridas na forma de avaliar as políticas públicas na América Latina tiveram forte apelo externo. Conforme Faria (2005), os organismos multilaterais, como Banco Mundial e Organização das Nações Unidas, aplicavam recursos em países latinos e precisavam de mecanismos de avaliação gerencial capazes de evidenciar a eficiência dos gastos públicos. 
Os organismos multilaterais foram importantes para que avaliações de políticas públicas começassem a ser feitas em alguns países, conforme Ramos e Schabbach (2012), fornecendo a metodologia e o conhecimento técnico necessário às implantações. Assim, conseguiu-se trocar experiências sobre gestão pública entre países como Brasil, Argentina e Chile, colocando a avaliação de políticas públicas em primeiro plano.

Dessa forma, acreditava-se que, com as informações geradas pelos indicadores de avaliação das políticas públicas, os tomadores de decisão promoveriam melhorias e mudanças rapidamente nos programas verificados, quando da constatação de ineficiência. Porém, segundo Faria (2005), não apenas a avaliação era considerada para promover modificações nas políticas públicas.

No Brasil, o Plano Plurianual (PPA) de 2004 a 2007 apresentou um sistema de avaliação, que, para Ramos e Schabbach (2012), assegurava a avaliação dos programas, disseminava a cultura da avaliação no âmbito federal, fornecendo subsídios para a tomada de decisão dos gestores, bem como para a formulação e implantação de novas políticas.

Para responder perguntas como: como estão evoluindo as políticas sociais, a quem atendem, quanto gastam, como operam e quais são seus resultados, o Ministério do Desenvolvimento Social (MDS), responsável pelo PBF, desenvolveu e implantou mecanismos para avaliar e monitorar políticas e programas sociais de sua competência, de acordo com Ramos e Schabbach (2012), por meio de um sistema informatizado. Assim, os gestores tiveram subsídios para aperfeiçoar os programas sociais e otimizar a aplicação de recursos públicos, bem como passaram a disponibilizar informações sobre o funcionamento dos programas e viabilizaram o controle social e a transparência da gestão.

Percebe-se, portanto, que o Brasil vem se alinhando às tendências mundiais de avaliação de políticas públicas, principalmente pelo aspecto da accountability, transparência da gestão e uso de indicadores, abrindo espaço para debates e estudos sobre novos métodos de avaliação (Ramos e Schabbach, 2012).

\section{Metodologia}

O presente estudo pretende analisar, por meio de uma pesquisa quali-quantitativa, sob a ótica dos beneficiários do Programa Bolsa Família (PBF), a eficácia do Programa quanto aos objetivos do mesmo. Para tanto, foi aplicada uma metodologia recente que, de acordo com Lefèvre e Lefèvre (2003), traduz-se por questionamentos abertos aos indivíduos que representam a coletividade, os quais ensejam discursos livres e sem amarras a um pensamento preconcebido, também conhecido como discurso do sujeito coletivo (DSC).

Conforme esclarece Lefèvre e Lefèvre (2003), a expressão do pensamento coletivo sobre determinado tema se dá por meio da transcrição dos depoimentos verbais coletados para o formato tabulado, e que usa como parâmetros as ideias centrais (IC), as ancoragens (AC) e as expressões-chave (ECH) semelhantes, identificadas no discurso individual, e que comporão, na primeira pessoa do singular, um único ou vários discurso-síntese. É importante 
observar que nesse tipo de pesquisa de representação a coleta de dados deve ser registrada na linguagem dos entrevistados, a fim de que estes possam imprimir suas opiniões e pensamentos como o são.

Na avaliação do tópico da pesquisa constatou-se a predominância de pesquisas descritivas na literatura, conforme Guerra e colaboradores (2012), Sá e Silva (2012) e Mourão, Ferreira e Jesus (2012). No entanto, considerando o quantitativo de beneficiários que recebem o Bolsa Família em Manaus e a necessidade de uma pesquisa que represente o pensamento coletivo refletindo a realidade sobre o tema, optou-se pela metodologia quali-quantitativa do DSC por amostragem de acessibilidade e conveniência, na forma de questionários abertos, usado também por Motta, Melo e Paixão (2012).

O método do discurso do sujeito coletivo traz a esta pesquisa uma nova forma de representação social na qual se organizam os dados qualitativos por meio de procedimentos sistemáticos e padronizados, sem, contudo, reduzir os depoimentos a números. Nesse sentido, o DSC analisa e extrai as ideias centrais de cada depoimento, possibilitando a criação de um discurso único do sujeito-que-fala, a partir dos discursos individuais.

De acordo com Lefèvre e Lefèvre (2003), o uso do DSC em um trabalho qualitativo permite ao pesquisador obter pensamentos, crenças e valores da coletividade com maior alcance e eficiência, em sua forma natural. Como consequência, o discurso coletivo poderá trazer respostas ricas, detalhadas e confiáveis com relação àquele tema.

Por outro lado os críticos dessa metodologia questionam suas eventuais falhas ou insuficiência em termos quantitativos. De fato, há limitações que o DSC não preenche, pois, em determinado momento, é desejável conhecer o percentual daquele discurso coletivo ou em que bairro ou faixa etária ele é mais frequente. Isso demonstra que as pesquisas qualitativas e quantitativas não são excludentes, mas, sim, complementares.

Ademais, os criadores da metodologia defendem que não existe regra que determine que pesquisas qualitativas devam ser aplicadas com pequenos ou grandes números. A expressiva quantidade de dados densos que os métodos quantitativos podem gerar, a exemplo deste trabalho, direciona o pesquisador para a delimitação do tamanho da amostra, por questões de ordem prática, o que não a invalida por essa razão, tendo em vista que a relevância estatística não é seu propósito.

O critério de escolha das perguntas abertas está relacionado com os objetivos do PBF considerando os três eixos principais já mencionados. Para contemplar esses objetivos, os entrevistados responderam livremente às duas perguntas propostas: 1) Fale um pouco sobre o que mudou na sua vida e na de sua família depois que passou a receber o benefício do Programa Bolsa Família; 2) Se fosse anunciado o fim do Programa Bolsa Família o que você faria? Por meio dessas perguntas a pesquisa pôde identificar se há correlação entre a percepção do beneficiário quanto às mudanças em sua vida e de sua família após a vinda deste recurso, comparando-os com os objetivos do Programa.

Importante destacar que não houve registro das informações básicas dos respondentes como nome ou endereço, uma vez que a ideia da pesquisa era captar o pensamento coletivo livre e sem intimidações de qualquer aspecto. Além do mais, as respostas fornecidas remetem 
ao cunho íntimo do seio familiar dos entrevistados, inclusive quanto ao cumprimento ou não das condicionalidades. Dessa forma, após a apresentação inicial dos pesquisadores, optou-se por esclarecer de imediato que os depoimentos orais seriam gravados e transcritos apenas no que concerne às respostas e com o objetivo estritamente acadêmico, podendo o entrevistado relatar adicionalmente o que lhe conviesse sobre o tema proposto.

Os questionários foram aplicados em datas distintas com 51 beneficiários moradores de Manaus (AM), escolhidos de forma aleatória em seu local de residência ou trabalho, a fim de se obter maior representatividade. Os pesquisadores receberam algumas indicações iniciais de pessoas que já recebem o PBF há mais de dois anos para a realização da entrevista e, ao final das mesmas, eventualmente o próprio respondente indicava outro beneficiário. Como a data e o local escolhido para as entrevistas não interfeririam nos resultados, as perguntas foram aplicadas em dias diferentes do mês por entrevistador, porém em ambiente segregado, o que permitiu a fala irrestrita e sem interrupções.

Em quase todos os depoimentos os pesquisadores necessitaram motivar os respondentes a detalharem melhor sua opinião com perguntas do tipo "e o que mais?" e "quer completar com mais alguma coisa?" e até mesmo repetindo a pergunta inicial de outra maneira. Alguns se encontravam tímidos ou produziam respostas curtas que poderiam não expressar totalmente o pensamento.

Para a delimitação amostral, foram entrevistados apenas beneficiários do sexo feminino, porém com estruturas familiares distintas. Nesse sentido, conforme Ibase (2008) e Pires (2008), a maioria dos titulares do PBF é de mulheres, em torno de 94\%, e essa titularidade é concedida preferencialmente às mulheres, pois, segundo Traldi, Almeida e Ferrante (2012), elas conhecem melhor as necessidades da família e tendem a utilizar o benefício com alimentação e com os filhos.

Sob outra ótica, nos últimos anos aumentou o número de mulheres que assumiram o papel de principal provedora da família, passando assim a ter maior relevância econômica e social, negligenciada em outras épocas. De acordo com o estudo do Ipea (2013), a quantidade de famílias chefiadas por mulheres cresceu 34,8\%, entre 1992 e 2012.

A tabulação dos dados obedeceu ao método do DSC, em que o primeiro passo é a criação do instrumento de análise de discurso (IAD) para cada questão, por meio do software MS Excel, e em seguida a transcrição dos respectivos depoimentos. Dos 51 entrevistados foi descartado apenas um depoente, visto que ele não pertencia ao universo de beneficiários moradores de Manaus.

Dos discursos coletados foram selecionadas primeiramente as expressões-chave (ECH), que consistem em ressaltar os segmentos mais relevantes dos discursos, sejam eles contínuos ou não. A partir das ECH foram identificadas as ideias centrais (IC) e catalogadas agrupando-se por semelhança (ex.: IC-A, IC-B etc.). As ICs têm por objetivo traduzir a opinião do entrevistado para seu significado real, isto é, naquilo que se quis dizer, o que pode estar eventualmente oculto. Finalmente, após análise dos IAD, foram reunidas as expressões-chave relacionadas às ideias centrais e produzido um único discurso, na forma original, representando a coletividade. 
Para fins de tratamento de dados, conforme orienta o próprio método, foi efetuada uma limpeza de trechos irrelevantes para a pesquisa como nomes, situações cotidianas e outros, focando-se apenas as ECs e extraindo dessas as ICs. Já na sintetização dos discursos, conforme orientam Motta, Melo e Paixão (2012), fez-se necessário o uso de conectores como pronomes e conjunções de modo que todo o discurso mantivesse um sentido claro e coerente sem, contudo, perder a originalidade da fala.

Outro elemento de auxílio no IAD é a ancoragem, que, ensina Lefèvre e Lefèvre (2003), nem sempre está presente nos depoimentos, posto que, para ser considerada como tal, deverá estar explícito no discurso alguma ideologia, credo ou teoria do respondente. Neste trabalho não foram identificadas tais manifestações e, por essa razão, eliminada do IAD.

A seguir, demonstra-se o resultado das análises dos dados, tendo como base o referencial teórico já exposto.

\section{Resultados e discussões}

No tratamento dos dados, em um primeiro momento, foram identificadas e categorizadas as ideias centrais (IC) mais frequentes nos discursos. Para a primeira pergunta foram identificadas sete ICs das quais foram analisadas cinco, considerando as suas representatividades para a pesquisa. Já na segunda pergunta foram registradas quatro ICs, sendo descartada, da mesma forma, a última. Vale ressaltar que, embora fossem 50 entrevistados, em alguns discursos foi identificada mais de uma IC, o que elevou a quantidade de respostas totais, conforme a frequência relativa demonstrada nas tabelas abaixo.

Tabela 1

Frequência das ideias centrais da pergunta 1

\begin{tabular}{|c|c|c|c|c|}
\hline \multicolumn{5}{|c|}{ Pergunta 1: O que mudou na vida da sua família depois que passou a receber o Bolsa Família? } \\
\hline \# & IDEIA CENTRAL & QTD & FREQ. RELATIVA & PERCENTAGEM \\
\hline IC-1 & O Programa Bolsa Família complementa a renda & 36 & 36 & $22 \%$ \\
\hline IC-2 & O Programa Bolsa Família melhorou a vida & 35 & 71 & $21 \%$ \\
\hline IC-3 & $\begin{array}{l}\text { O Programa Bolsa Família melhorou a/na educação dos meus } \\
\text { filhos }\end{array}$ & 33 & 104 & $20 \%$ \\
\hline IC-4 & $\begin{array}{l}\text { O Programa Bolsa Família melhorou a alimentação da minha } \\
\text { família }\end{array}$ & 32 & 136 & $19 \%$ \\
\hline IC-5 & $\begin{array}{l}\text { O Programa Bolsa Família melhorou a/na saúde dos meus } \\
\text { filhos }\end{array}$ & 18 & 154 & $11 \%$ \\
\hline IC-6 & O Programa Bolsa Família permitiu o acesso ao trabalho & 4 & 158 & $2 \%$ \\
\hline IC-7 & O valor pago pelo Programa Bolsa Família é pouco & 4 & 162 & $2 \%$ \\
\hline TOTAL & & 162 & 162 & $100 \%$ \\
\hline
\end{tabular}

Fonte: Elaboração própria. 
Tabela 2

Frequência das ideias centrais da pergunta 2

\begin{tabular}{|llccc|}
\hline \multicolumn{2}{|l|}{ Pergunta } & 2: O que você faria se o PBF acabasse? & & \\
\hline$\#$ & IDEIA CENTRAL & QTD & FREQ. RELATIVA & PERCENTAGEM \\
IC-8 & Se o Programa Bolsa Família acabasse eu iria trabalhar & 29 & 29 & $39 \%$ \\
IC-9 & Eu e minha família ficaríamos desamparadas com o fim do & 22 & 51 & $30 \%$ \\
& Programa Bolsa Família & & 71 & $27 \%$ \\
IC-10 & Eu ficaria conformado com o fim do Programa Bolsa Família & 20 & 73 & $2 \%$ \\
IC-11 & O Governo criaria outro programa & 2 & 73 & $100 \%$ \\
TOTAL & & 73 & 73 & \\
\hline
\end{tabular}

Fonte: Elaboração própria.

Para a pergunta 1 foram descartadas as IC-6 e IC-7, uma vez que possuem pouca representatividade nos discursos coletivos, aproximadamente $2 \%$ cada. Da mesma forma, a IC- 11 da pergunta 2 também foi desconsiderada, pois representa apenas $2 \%$ do que foi relatado nas entrevistas.

A partir dessa análise quantitativa foram construídos os DSC para cada IC e analisados qualitativamente sob o prisma dos objetivos do Programa, isto é, se a percepção do beneficiário condiz com os objetivos do PBF como programa de transferência de renda condicionada. As ideias centrais descartadas serão examinadas após a análise dos discursos válidos.

\subsection{Análise dos resultados}

Quadro 1

Ideia central 1

\begin{tabular}{|l|}
\hline IC-1 \\
\hline O Programa Bolsa Família complementa a renda da minha família \\
O Bolsa Família é uma ajuda a mais na minha renda, a gente fica esperando todo mês esse dinheiro pra comprar alguma \\
coisa pra casa, isso ajuda muito, né. Com a Bolsa Família consegui melhorar a renda, passei a juntar esse valor ao dinheiro do \\
meu trabalho, isso faz diferença né, porque o que ganho não é muito, e só o dinheiro do trabalho não dá nem pra sobreviver. \\
Antes era tudo contadinho, não sobrava pra nada. Agora preciso da Bolsa Família, mesmo sendo pouco, não tenho como tirar \\
de outro canto, por isso faço tudo direitinho para não perder. Queira ou não é um dinheiro extra, né. \\
\hline
\end{tabular}

Fonte: Elaboração própria.

Pelo DSC da IC-1 infere-se que o beneficiário compreende o benefício do Bolsa Família como um complemento da renda familiar, justamente para auxiliar no provimento de 
sustento para a família. Nesse sentido, o estudo de Rosinke e colaboradores (2011) identificou que 80,71\% dos beneficiários narraram que a sua situação financeira melhorou após ingressarem no PBF.

Outra ideia relatada no DSC é a aquisição de objetos para casa com recursos do PBF. Esse fato já havia sido apontado por Castro e colaboradores (2009), ao concluírem que 60\% dos beneficiários empregam os recursos na compra de artigos de uso pessoal, e ainda em utensílios para o lar.

Nesse âmbito, sobre aquisição de artigos para o lar, Rosinke e colaboradores (2011) perceberam que a renda fixa mensal advinda do benefício do Bolsa Família influencia no acesso ao microcrédito para o beneficiário, permitindo a aquisição de equipamentos e eletrodomésticos.

Em outro sentido, percebe-se que o beneficiário do PBF reconhece a importância do benefício para a sua renda; assim, para continuar assistido, este entende a necessidade de cumprimento das condicionalidades. Essa dependência em parte explica-se pelo perfil financeiro dos beneficiários, resultado da baixa instrução educacional dos seus membros e consequente alocação em postos de trabalho operacionais.

Para Traldi, Almeida e Ferrante (2012), a renda média total das famílias beneficiárias do Bolsa Família mostra que mais da metade das famílias, cerca de 64\%, possui renda menor do que um salário mínimo. Com relação à escolaridade, o Ibase (2008) identificou que 56\% dos titulares dos benefícios estudaram até o ensino fundamental. Acrescentam Traldi, Almeida e Ferrante (2012), ao descreverem que a maioria dos titulares sabe ler e escrever, que apenas $20 \%$ possuem ensino médio completo e $3 \%$, o ensino superior.

Quadro 2

Ideia central 2

\begin{tabular}{|l|}
\hline IC-2 \\
\hline O Programa Bolsa Família melhorou a vida da minha família \\
O Bolsa Família é bom, é uma benção, ele veio pra nos ajudar a sustentar a casa, né. Desde que comecei a receber, percebi \\
as melhoras, e isso mudou minha vida, foi uma coisa muito boa pra gente. A maioria das pessoas que conheço recebe e gosta \\
da Bolsa Família. Mesmo que seja pouco, facilita bastante, já que o meu salário não é suficiente. E ainda é bom porque tem \\
uma data certa pra pagar.
\end{tabular}

Fonte: Elaboração própria.

De acordo com o DSC da IC-2, os beneficiários do Programa Bolsa Família relataram que o recebimento do benefício provocou efeitos positivos nas vidas de suas famílias, bem como na vida de outros beneficiários que eles conhecem. A percepção dos beneficiários surge com o comparativo entre o período anterior e posterior ao recebimento do benefício, principalmente relacionado ao aumento da renda e, consequentemente, da capacidade de consumo.

Nesse sentido, Sá e Silva (2012) constataram que para 71,25\% dos beneficiários de sua amostra a situação financeira ficou melhor a partir da inserção no Programa Bolsa Família. Corroboram Rosinke e colaboradores (2011), ao constatarem que 54,39\% dos entrevistados 
de sua pesquisa consideram o Programa bom, 36,84\% consideram o Programa ótimo e apenas 8,77\% consideram o Programa regular.

Essa mesma percepção positiva suscitada no DSC foi traduzida na pesquisa de Castro e colaboradores (2009) que, com base em uma amostra de 6.001 entrevistados, identificaram que $72 \%$ consideraram que o Bolsa Família traz mais coisas boas para o Brasil e melhora a vida das pessoas. Essa avaliação é ampliada quando os pesquisados conhecem algum beneficiário do $\mathrm{PBF}$, elevando esse percentual para 77\%. No mesmo sentido, o fato de conhecer ou não algum beneficiário influencia em uma maior percepção de efetividade dos objetivos do PBF.

Nesse âmbito, o beneficiário também relatou que o valor do dinheiro repassado não supre todas as necessidades para a emancipação sustentada da família. Porém, ressalta a organização do Programa quanto à efetividade do pagamento no calendário programado. Segundo Fonteles e colaboradores (2011), foram identificados como principais aspectos que melhor representam a percepção dos beneficiários sobre o PBF: a certeza do recebimento mensal, a autonomia financeira, o aumento do poder de compra e a independência adquirida a partir da adesão ao Programa.

Quadro 3

Ideia central 3

\begin{tabular}{|l|}
\hline IC-3 \\
\hline O Programa Bolsa Família melhorou a/na educação dos meus filhos \\
Pra mim o que mudou foi que as crianças têm que ir pra escola todo dia porque o governo cobra mesmo, mas eu nunca gostei \\
que eles faltassem não. Hoje elas não precisam trabalhar. E, com esse dinheiro, eu invisto no estudo deles e ajudo a comprar \\
o material escolar e a farda que eles queriam. Antes tinha que reservar uma parte do meu salário para isso, mas agora compro \\
com o dinheiro do Bolsa Família. O rendimento da minha filha na escola até melhorou. Cheguei a pagar curso de informática \\
para ela com o dinheiro do Bolsa Família. Os meninos também andavam com os pés descalços e agora posso comprar sapato, \\
roupa, merenda e vale-transporte para a escola, pois eu trabalho e não tem quem vai buscar ele na escola.
\end{tabular}

Fonte: Elaboração própria.

Segundo o DSC da IC-3, nota-se que a percepção do beneficiário quanto à condicionante educação é condizente com os objetivos do PBF. A maioria relatou que parte dos recursos financeiros são usados na compra de material escolar e em outros itens, acessórios a este, como vestuário e calçados. Muitos ainda se preocupam com a questão do transporte escolar e até com cursos complementares.

Nesse sentido, este DSC está condizente com o estudo do Ibase (2008), que constatou que $46 \%$ dos titulares do PBF gastam o dinheiro com a compra de material escolar, e na região Norte esse percentual chega a 63,5\%, e ainda outros $37 \%$ gastam o benefício com a compra de vestuário.

Da mesma forma, a frequência escolar é item de destaque no discurso, uma vez que os pais e responsáveis sofrem a cobrança do poder público para que se mantenha o benefício, o que também os motiva a manter os filhos na escola. Para Fonteles e colaboradores 
(2011), no campo da educação, a principal prioridade dos beneficiários está na aquisição de material escolar e na manutenção dos filhos na escola para a continuidade no recebimento do benefício mensal.

Importante registrar que, de acordo com Guerra e colaboradores (2012), um dos objetivos do compromisso das famílias com as regras do PBF é proporcionar um estímulo ao desenvolvimento de capital humano. Isso se interpreta no discurso pela percepção da natureza do benefício, que tem como objetivo, ainda, romper o ciclo intergeracional da pobreza nas famílias, por meio da educação.

Assim, o suporte financeiro, segundo Lindert e colaboradores (2007), é decisivo na permanência das crianças na escola, uma vez que existem custos diretos e indiretos para a manutenção da frequência escolar, como transporte e material escolar, os quais as famílias não estariam preparadas para arcar.

Nessa direção, sobre a percepção da consecução dos objetivos do Programa Bolsa Família, Castro e colaboradores (2009) verificaram que $83 \%$ da população reconhecem que o PBF ajuda a manter as crianças na escola, e 74\% entendem que o benefício traz melhorias na educação das crianças.

Quadro 4

Ideia central 4

IC-4

O Programa Bolsa Família melhorou a alimentação da minha família

Com o dinheiro que recebo posso comprar alimento, e também ajuda na compra de um gás. Todo mês eu tenho o que garante a comida. Antes não dava pra comprar muita coisa, agora meus filhos podem comer bem. Lá em casa não falta mais jaraqui nem farinha. Faço o rancho de casa e quando recebo o dinheiro vou pagando. Muitas pessoas não tinham nem o que comer, hoje já têm. Hoje não falta nada em casa, a gente é pobre, mas pelo menos tem o que comer. Tem feijão, arroz, uma mistura, todo dia. Antes tinha alimentação, mas não tanto como agora. Isso é muito importante, pois hoje em dia a gente gasta muito com alimentação, principalmente aqui na nossa região.

Fonte: Elaboração própria.

Pelo exame do DSC da IC-4, pode-se interpretar que os beneficiários constataram um alívio imediato da pobreza e da fome após o ingresso no PBF. A maior parte mencionou que, antes do PBF, a alimentação na sua família era escassa e de pouca qualidade, realidade que foi modificada desde a inserção no Programa. Nesse sentido, muitos assistidos interpretam o benefício como fundamental na redução da insegurança alimentar. Segundo Sá e Silva (2012), os beneficiários percebem que os recursos do PBF contribuíram para um maior acesso à compra de alimentos pelos beneficiários, bem como promoveram um aumento no número de refeições das famílias.

Conforme o Ibase (2008), de acordo como 87\% dos titulares, o benefício é gasto principalmente com alimentação; essas famílias gastam, em média, R 200 (duzentos reais) mensais com alimentação, o que representa em média $56 \%$ da renda familiar total. A citada pesquisa 
constatou que, quanto mais pobre a família, maior a proporção da renda gasta com alimentação; assim também percebeu o estudo de Rosinke e colaboradores (2011), em que 68,42\% dos beneficiários afirmaram gastar a renda recebida por meio do PBF com a alimentação das pessoas residentes no domicílio.

Segundo os entrevistados, o PBF teve, ainda, parcela de colaboração na inclusão dos beneficiários na faixa da segurança alimentar. A comparação entre a situação atual e a anterior ao ingresso no Programa registrou impactos positivos com o advento do PBF. Sá e Silva (2012) apontaram que depois da inclusão no PBF constataram-se melhorias significativas nas condições de vida das famílias beneficiadas, principalmente na área de alimentação. Para Traldi, Almeida e Ferrante (2012), os principais gastos das famílias com os benefícios do Bolsa Família são na maioria com a alimentação.

Conclui-se que entre os beneficiários entrevistados foi possível registrar que, quanto ao combate à fome e promoção da segurança alimentar e nutricional, o PBF tem conseguido alcançar seus objetivos. Relataram-se resultados expressivos quanto à elevação do poder de compra dos beneficiários do PBF, fato que possibilitou o aumento do consumo de alimentos.

Sobre segurança alimentar e nutricional, o estudo do Ibase (2008) pesquisou o que ocorreu com a alimentação da família após o recebimento do benefício pelo PBF, e dentre os titulares, 74\% responderam que aumentou a quantidade de alimentos que já consumiam, $70 \%$ responderam que acrescentou na variedade de alimentos, e 63\% explicaram que o benefício ajudou na compra de alimentos que as crianças gostam.

Na mesma vertente, Sá e Silva (2012) concluíram que o benefício do Bolsa Família também influencia no aumento dos dias cobertos pelos alimentos comprados, bem como numa maior variedade nutricional das refeições diárias.

Quadro 5

Ideia central 5

\begin{tabular}{|l|}
\hline IC-5 \\
\hline O Programa Bolsa Família melhorou a/na saúde dos meus filhos \\
O Bolsa Família ajuda muito porque é também com esse dinheiro que eu compro fralda e medicamentos para os meus filhos \\
pois muitas vezes não temos um dinheiro extra para comprar. Meu filho passou a ir mais no posto de saúde, no mínimo de \\
seis em seis meses, para pesar e medir. Agora vou com mais frequência e fico também mais atenta para as vacinas, pois eles \\
cobram mesmo.
\end{tabular}

Fonte: Elaboração própria.

Por este discurso, pode-se identificar a preocupação do beneficiário em não perder a renda do programa por deixar de cumprir as condicionalidades do PBF. O beneficiário percebe a importância de encaminhar os filhos ao posto de saúde, periodicamente, para medição, pesagem e atualização da cartela de vacinação. Porém, conforme ensinam Mourão, Ferreira e Jesus (2012), o mote do PBF não é tão somente estabelecer o caráter punitivo, de forma a 
garantir cumprimento das condicionalidades, mas, sim, ampliar o acesso aos direitos sociais, à rede de serviços públicos.

Registra-se, ainda, outra finalidade percebida no DSC da IC-5 para o uso dos recursos do PBF, além da alimentação e educação, que é a compra de remédios e fraldas, aos quais, de outra forma, não teriam acesso ou teriam um acesso limitado. Nesse sentido, foi examinado pelo Ibase (2008) que $22 \%$ dos titulares priorizam o dinheiro do benefício para compra de remédios.

De acordo com Rasella (2013), o Programa Bolsa Família contribui amplamente para o decréscimo no índice de mortalidade infantil, especialmente na diminuição de mortes atribuídas a doenças relacionadas à pobreza, como diarreia e má nutrição em crianças menores de cinco anos. As vacinas em dia, a subnutrição controlada, o acompanhamento de nutrizes e o pré-natal das gestantes trouxeram como consequência uma redução de $17 \%$ no índice de mortalidade infantil entre os anos de 2004 e 2009.

Interpreta-se ainda pelos discursos que esse resultado não está necessariamente vinculado ao recurso financeiro, mas às condicionantes impostas. A grande maioria tem consciência da necessidade de cuidar da saúde e do desenvolvimento dos filhos, mas o que determina seu cumprimento à risca é a exigência do Programa.

Quadro 6

Ideia central 8

\begin{tabular}{|l|}
\hline IC-8 \\
\hline Se o Programa Bolsa Família acabasse eu iria trabalhar \\
A gente tem que ficar preparada porque não é pra sempre. Não podemos depender só disso, temos que ter um meio de \\
conseguir um trabalho. Além disso, o Bolsa Família é só uma ajuda e não um dinheiro total pra sobreviver. Eu ia me programar \\
né porque já senti na pele o que é ficar sem, faço ideia agora se não tiver mais. Então, iria procurar uma oportunidade, pra \\
fazer qualquer coisa. Se tiver trabalho eu vou, inclusive meus filhos também irão. Eu estou me preparando, já estou procurando \\
emprego.
\end{tabular}

Fonte: Elaboração própria.

Neste discurso o beneficiário demonstra consciência da temporalidade do programa, seja porque há alguma possibilidade de que um dia ele acabe ou porque, de alguma forma, o beneficiário já não se enquadrará mais nos requisitos mínimos para continuar recebendo o benefício. Contudo, poucos relataram a preocupação prévia quanto à capacitação para o acesso ao mercado de trabalho, conforme demonstrado nos dados da IC-6.

Noutro giro, também foi relatada no discurso a possibilidade de inserir os filhos no mercado de trabalho, se o PBF acabasse, o que deve ser visto como um alerta. De acordo com a pesquisa de Guerra e colaboradores (2012), um terço das crianças assistidas trabalha, sendo ainda que $28 \%$ dos beneficiários desconhecem a proibição do trabalho infantil pelo Programa.

Portanto, nesse aspecto, o PBF tem falhado, considerando que uma das suas finalidades é a erradicação do trabalho infantil. Faz-se necessária uma abordagem bilateral para, de um 
lado, coibir essa prática com fiscalização mais específica pelo MDS e, do outro, por meio de campanhas educativas para a população, reforçando os efeitos nocivos no longo prazo da entrada precoce no mercado de trabalho de crianças e jovens.

Quadro 7

Ideia central 9

\begin{tabular}{|l|}
\hline IC-9 \\
\hline Eu e minha família ficaríamos desamparadas com o fim do Programa Bolsa Família \\
Se acabar vai fazer muita falta, queira ou não já faz parte da nossa renda né, já contamos com essa ajuda que o governo dá. \\
la ficar complicado, é um dinheirinho a mais, e às vezes vem na hora certa. la ser uma situação muito difícil, não saberia o \\
que fazer, não temos outra ajuda, iria me prejudicar bastante se tivesse que tirar da minha renda. Também seria ruim, porque \\
muita gente depende disso. Não sei o que iria fazer. Espero que não acabe tão cedo. \\
\hline
\end{tabular}

Fonte: Elaboração própria.

Nesse DSC, o beneficiário demonstra que ficaria desamparado, caso o Programa Bolsa Família acabasse. Esse fato ocorre porque a maioria dos beneficiários cria uma relação de dependência com o benefício e não consegue planejar ou conceber o término do Programa. Segundo Sá e Silva (2012), a dependência contínua pela assistência governamental constitui um fator preocupante, visto o PBF definir a emancipação das famílias como um dos seus objetivos.

Por isso, Faria (2005) destacou que não apenas a avaliação deve ser considerada para promover modificações nas políticas públicas. Ramos e Schabbach (2012) recordaram que os gestores passaram a dispor de subsídios para aperfeiçoar os programas sociais e otimizar a aplicação de recursos públicos, bem como disponibilizaram informações sobre o funcionamento dos programas e viabilizaram o controle social e a transparência da gestão.

\section{Quadro 8 \\ Ideia central 10}

\begin{tabular}{|l|}
\hline IC-10 \\
\hline Eu ficaria conformado com o fim do Programa Bolsa Família \\
Ficaria triste porque é uma ajuda pra gente. Iria ser ruim, mas a gente tinha que se conformar. Deixava na mão de Deus. Ainda \\
não pensei em me preparar pra sair do programa. la ter que me manter como me mantinha antes. Ninguém ia poder fazer nada, \\
porque assim como o governo dá, ele tira. Se não me derem mais eu não posso fazer nada, tenho que ficar numa boa. Ora, se \\
acabar, acabou! O que eu ia poder fazer?! Não sabemos até quando vai continuar. Não iria deixar de tocar minha vida pra frente. \\
Mas caso aconteça não poderia fazer nada, temos que estar preparada para tudo.
\end{tabular}

Fonte: Elaboração própria.

O DSC da IC-10 denota claramente o conformismo do beneficiário caso o Programa Bolsa Família acabasse. Este conformismo é explicado em parte pela percepção político-eleitoral 
que o beneficiário tem do Programa. Percepção esta, de dimensão cultural, já explicada na discussão da IC-9 por Lavinas, Cobo e Veiga (2012).

Para Guerra e colaboradores (2012), os beneficiários devem ter a noção que o Bolsa Família se trata de uma política de caráter social amplo, fundamental em países em desenvolvimento. Nesse sentido, é necessário planejar ações que conscientizem a população sobre os reais objetivos do Programa, como campanhas educativas de âmbito nacional, de modo a eliminar a conotação política-eleitoral entendida pelo beneficiário em função da assistência do PBF.

\subsection{Fatores com pouca representatividade}

As IC-6 e IC-7, referentes à primeira pergunta da pesquisa, foram registradas em quatro discursos diferentes cada uma. A primeira trata de um dos objetivos do PBF, que é o incentivo à emancipação sustentada das famílias que vivem em situação de pobreza e extrema pobreza.

Nesse sentido, afirmam Guerra e colaboradores (2012) que é necessário examinar se os beneficiários do PBF compreendem o caráter transitório do programa, bem como fomentar ações no intuito de estes obterem outras fontes de renda. Do contrário, esse objetivo do PBF, especificamente, não será cumprido, podendo gerar efeitos reversos.

Nesta esteira, a falta de capacitação e a baixa escolaridade dos beneficiários do PBF são fatores que dificultam o acesso a postos de trabalho. Desse modo, Traldi, Almeida e Ferrante (2012) sugerem que o PBF seja integrado a outros programas, de forma a obter melhoria nas condições de qualificação profissional dos beneficiários.

Em outra vertente, a ideia de que o valor recebido pelo PBF é insuficiente foi identificada em quatro discursos. Para famílias com muitos integrantes e que têm o PBF como única fonte de renda, provavelmente os valores recebidos serão insuficientes para satisfazer as necessidades de alimentação, saúde, educação e assistência social de todos os seus integrantes.

\section{Considerações finais}

Este trabalho teve por objetivo analisar a eficácia do PBF sob a ótica dos beneficiários de Manaus (AM). Especificamente, apontou os objetivos do PBF, examinou-os conforme a percepção dos 50 beneficiários entrevistados, aplicando a ferramenta metodológica do discurso do sujeito coletivo (DSC), e interpretou seus resultados.

Os objetivos do PBF previstos no Decreto № 5.209/2004, que regulamenta o Programa Bolsa Família, foram identificados e comparados com os discursos construídos por meio do DSC, quais sejam: promover o acesso à rede de serviços públicos, em especial, de saúde, educação e assistência social; combater a fome e promover a segurança alimentar e nutricional; estimular a emancipação sustentada das famílias que vivem em situação de pobreza e extrema pobreza; combater a pobreza e promover a intersetorialidade, a complementaridade e a sinergia das ações sociais do poder público. 
É importante ressaltar que os objetivos e condicionalidades do PBF foram relatados espontaneamente pelos beneficiários durante a pesquisa. Não houve o direcionamento de perguntas a determinados objetivos em detrimento de outros. Os entrevistados ficaram livres para responder às duas perguntas da maneira como quisessem, relatando exatamente as suas percepções quanto à eficácia do $\mathrm{PBF}$ e ao cumprimento de suas condicionalidades.

Primeiramente, pode-se interpretar que o beneficiário percebe o valor recebido como um complemento da renda familiar, funcionando justamente para auxiliar no provimento do sustento da sua família, por meio da aquisição de alimentos, material escolar, vestuário, calçados e demais acessórios, por exemplo.

Os beneficiários do PBF relataram que o recebimento do benefício gerou efeitos positivos nas vidas de suas famílias. A comparação entre o período anterior e posterior à inserção no PBF fez com que os beneficiários relatassem mudanças relacionadas, principalmente, ao aumento da renda e da capacidade de consumo familiar.

Pode-se interpretar ainda que os beneficiários perceberam o objetivo e a condicionalidade referente à educação. A maioria relatou que parte dos recursos financeiros é aplicada na compra de material escolar e em outros itens, acessórios a este, como vestuário e calçados. Muitos ainda demonstraram preocupação com a questão do transporte escolar e com cursos complementares para seus dependentes. Da mesma forma, a frequência escolar foi item de destaque no discurso, pois, para manutenção do benefício, os filhos devem comparecer à escola.

Os beneficiários entrevistados constataram um alívio imediato da pobreza e da fome após ingressarem no PBF. Muitos recordaram que anteriormente ao PBF a alimentação familiar era escassa e após a inserção no Programa puderam prover uma maior quantidade de alimentos para a família. Foi marcante a percepção de que o PBF contribuiu para a redução da insegurança alimentar, diminuindo o número de famílias que não se nutriam ou alimentavam-se em menores quantidades diárias. Conclui-se que entre os beneficiários entrevistados em Manaus (AM) foi possível registrar que, quanto ao combate à fome e promoção da segurança alimentar e nutricional, o PBF tem conseguido alcançar seus objetivos.

A preocupação do beneficiário em ser excluído do Programa por deixar de cumprir as condicionalidades do $\mathrm{PBF}$, principalmente no tocante à saúde, também foi identificada na pesquisa. O beneficiário demonstrou conhecimento dessa condicionalidade, fazendo com que seus filhos frequentem o posto de saúde, periodicamente, para medição, pesagem e atualização da cartela de vacinação.

A maioria dos beneficiários demonstrou consciência da temporalidade do programa, porém poucos expressaram alguma preocupação com a sua capacitação profissional, isto é, apenas uma minoria está se qualificando para entrar no mercado de trabalho ou para obter um emprego melhor. Os entrevistados demonstram que ficariam desamparados caso o Programa Bolsa Família acabasse. Esse fato ocorre porque a maioria dos beneficiários nutre uma relação de dependência com o benefício e não consegue planejar ou conceber o término do Programa. Noutra vertente, a maioria dos entrevistados relatou que ficaria conformada com o fim do Programa Bolsa Família e isso denota, em parte, a percepção político-eleitoral que o beneficiário tem do Programa. 
Dessa forma, conclui-se que, dentre os entrevistados em Manaus (AM), o objetivo de instigar a emancipação sustentada das famílias que vivem em situação de pobreza e extrema pobreza não apontou bom desempenho. A grande maioria não expressa uma ideia de transitoriedade do PBF. Logo, esse objetivo do Programa não foi atendido plenamente.

Ainda registrou-se a possibilidade de trabalho infantil, caso o PBF acabasse. Seria o descumprimento de uma condicionalidade do Programa, pois se exige a frequência escolar das crianças e adolescentes para manutenção do benefício. Caso contrário, o beneficiário é excluído do PBF e deixa de receber o valor correspondente.

De todo o exposto, conclui-se que o PBF sob a ótica dos beneficiários de Manaus (AM) é parcialmente eficaz, considerando que os objetivos de promoção do acesso à rede de serviços públicos, em especial, de saúde, educação e assistência social, o combate à fome e a pobreza conseguiram ser percebidos nos DSC dos beneficiários. Contudo, noutro giro, outros objetivos foram pouco percebidos, estes relacionados à emancipação sustentada das famílias e à sinergia das ações governamentais. Deste mesmo modo, o estudo de Mendes, Barbosa e Rodrigues (2009) concluiu que o PBF não tem exercido uma função emancipatória, voltada à efetivação da cidadania, como fomento à vida associativa, e, principalmente, à participação e ao conhecimento sobre os direitos políticos pelos beneficiários.

Na mesma direção, identificou-se a ausência da percepção dos beneficiários sobre a sinergia das ações do poder público em todas as suas esferas no gerenciamento do PBF, creditando apenas a imagem do governo federal, e não visualizando as contribuições dos governos municipal e estadual na efetivação do Programa.

Nesse sentido, faz-se necessário o desenvolvimento de ações conjuntas intergovernamentais, visando prover a plena eficácia dos objetivos do Programa Bolsa Família. E, primordialmente, com acompanhamento e avaliação contínua nos municípios amazônicos, considerando suas peculiaridades regionais, de modo a não incorrer na "gestão da pobreza" apontada por Demo (2006).

Como desdobramentos desta pesquisa, propõem-se novos estudos sobre a eficácia de programas sociais com transferência de renda no Brasil, aplicando outras metodologias e comparando seus resultados com os de outras pesquisas similares. Da mesma forma, sugere-se o desenvolvimento de pesquisas dedicadas à emancipação sustentada das famílias por meio de programas sociais, de maneira a identificar possíveis lacunas no desenvolvimento e acompanhamento de políticas públicas que tenham essa finalidade ou como parte de um objetivo maior, como é o caso do Programa Bolsa Família.

\section{Referências}

BRASIL. Decreto $n^{\circ}$ 5.209, de 17 de setembro de 2004. Regulamenta a Lei $n^{\circ} 10.836$, de 9 de janeiro de 2004, que cria o Programa Bolsa Família, e dá outras providências. Brasília: 2004. Disponível em: <www.planalto.gov.br/ccivil_03/_ato2004-2006/2004/decreto/D5209compilado.htm>. Acesso em: 26 mar. 2014. 
CASTRO, Henrique C. O. et al. Percepções sobre o Programa Bolsa Família na sociedade brasileira. Revista Opinião Pública, Campinas, v. 15, n. 2, p. 333-355, nov. 2009.

DEMO, Pedro. Pobreza política: a pobreza mais intensa da pobreza brasileira. Campinas: Autores Associados, 2006.

DENUBILA, Laís A.; FERREIRA, Marco A. M.; MONTEIRO, Doraliza A. A. Programa Bolsa Família: análise da trajetória dos indicadores sociais em Minas Gerais. In: ENANPAD, 34., 2010, Rio de Janeiro. Anais... Rio de Janeiro: Anpad, 2010. Disponível em: <www.anpad.org.br/ evento.php? acao $=$ trabalho\&cod_edicao_subsecao $=626 \&$ cod_evento_edicao $=53 \&$ cod_edicao_ trabalho $=11688>$. Acesso em: 22 maio 2013.

ESTRELLA, Juliana; RIBEIRO, Leandro M. Qualidade da gestão das condicionalidades do Programa Bolsa Família: uma discussão sobre o índice de gestão descentralizada. Rev. Adm. Pública, v. 42, n. 3, p. 625-641, maio/jun. 2008.

FARIA, Carlos A. P. de. A política da avaliação de políticas públicas. Revista Brasileira de Ciências Sociais, São Paulo, v. 20, n. 50, p. 97-169, out. 2005.

FLEURY, Sonia. Políticas sociais e democratização do poder local. In: VERGARA, Sylvia C.; CORREAA, Vera L. A. (Org.). Propostas para uma gestão pública municipal efetiva. Rio de Janeiro: Ed. FGV, 2003. v. 2, p. 91-115.

FIGUEIRÓ, Ana L. Entre o assistencialismo e a emancipação: uma análise da relação entre estado e sociedade civil, a partir das experiências do Programa Bolsa Família no entorno do Distrito Federal. Sociedade e Estado, v. 25, n. 1, p. 145-146, 2010.

FONTELES, Auridete L. et al. Programa Bolsa Família e mobilidade social: sociabilização, trabalho e educação nas famílias beneficiadas. In: ENANPAD, 35., 2011, Rio de Janeiro. Anais... Rio de Janeiro: Anpad, 2011. Disponível em: <www.anpad.org.br/evento.php?acao=trabalho\&cod_edicao_ subsecao $=736 \&$ cod_evento_edicao $=58 \&$ cod_edicao_trabalho $=13019>$. Acesso em: 22 maio 2013.

GUERRA, Ana C. et al. Programa Bolsa Família: uma análise sob o ponto de vista dos usuários. In: ENANPAD, 36., 2012, Rio de Janeiro. Anais... Rio de Janeiro: Anpad, 2012. Disponível em: $<$ www.anpad.org.br/evento.php?acao $=$ trabalho\&cod_edicao_subsecao $=848 \&$ cod_evento_ edicao $=63 \&$ cod_edicao_trabalho $=14415>$. Acesso em: 22 maio 2013.

HOFLING, Eloísa de M. Estado e políticas (públicas) sociais. Cadernos Cedes, v. 21, n. 55, p. 30-41, nov. 2001.

IBASE. Instituto Brasileiro de Análises Sociais e Econômicas. Repercussões do Programa Bolsa Família na segurança alimentar e nutricional das famílias beneficiadas. 2008. Disponível em: <www.ibase. br/pt/wp-content/uploads/2011/06/segal-repercuss\%C3\%B5es-do-bolsa-fam\%C3\%ADlia.pdf>. Acesso em: 11 jun. 2013.

IPEA. Instituto de Pesquisa Econômica Aplicada. Pnad 2013 - Duas décadas de desigualdade e pobreza no Brasil medidas pelo Pnad/IBGE. 2013. Disponível em: <www.ipea.gov.br/portal/images/ stories/PDFs/comunicado/131001_comunicadoipea159.pdf > Acesso em: 25 mar. 2014. 
KERSTENETZKY, Celia L. Redistribution and development? the political economy of the Bolsa Família Program. Dados - Revista de Ciências Sociais, Rio de Janeiro, v. 52, n. 1, p. 53-83, 2009.

LAVINAS, Lena; COBO, Barbara; VEIGA, Alinne. Bolsa Família: impacto das transferências de renda sobre a autonomia das mulheres pobres e as relações de gênero. Revista Latinoamericana de Población, v. 6, n. 10, p. 32, enero/jun. 2012.

LEFÈVRE, Fernando; LEFÈVRE, Ana M. C. O discurso do sujeito coletivo. Um novo enfoque em pesquisa qualitativa (desdobramentos). Caxias do Sul, RS: Educs, 2003.

LINDERT, Kathy et al. The nuts and bolts of Brazil's Bolsa Família Program: implementing conditional cash transfers in a decentralized context. Social Protection Discussion Paper. Series of World Bank Working Papers, n. 709, may 2007. Disponível em: <http://josiah.berkeley.edu/2008Fall/ ARE253/PN3\%20Services\%20for\%20Poor/Brazil_BolsaFamilia.pdf>. Acesso em: 22 jun. 2013.

MDS. Ministério do Desenvolvimento Social e Combate à Fome. Relatório de informações sociais do Bolsa Família e Cadastro Único: Manaus/AM. 2013. Disponível em: < http://aplicacoes.mds.gov. br/sagi/RIv3/geral/relatorio.php\#>. Acesso em: 7 jun. 2013.

MELO, Marcus A. As sete vidas da agenda pública brasileira. In: RICO, Elizabeth M. (Org.). Avaliação de políticas sociais: uma questão em debate. São Paulo: Cortez, 1998. p. 11-28.

MELO, Marcus A. Estado, governo e políticas públicas. In: MICELI, Sérgio (Org.). O que ler na ciência social brasileira (1970-1995). São Paulo: Sumaré, 1999. v. 3, p. 59-100.

MARSIGLIA, Regina M. G.; SILVEIRA, Cássio; CARNEIRO JUNIOR, Nivaldo. Políticas sociais: desigualdade, universalidade e focalização na saúde no Brasil. Saúde e Sociedade, v. 14, n. 2, p. 69-76, 2005.

MENDES, Vera L. P. S.; BARBOSA, Angela M. G.; RODRIGUES, Jorgas M. Gestão dos serviços públicos e participação cidadã: estudo com os beneficiários do Programa Bolsa Família. Revista de Administração Contemporânea, Curitiba, v. 13, n. especial, p. 105-120, jun. 2009.

MOTTA, Gustavo da S.; MELO, Daniel R. A. de; PAIXÃO, Roberto B. O jogo de empresas no processo de aprendizagem em administração: o discurso coletivo de alunos. Revista da Administração Contemporânea, Rio de Janeiro, v. 16, n. 3, p. 342-359, maio/jun. 2012.

MOURÃO, Luciana; FERREIRA, Maria C.; JESUS, Anderson M. de. Evaluation of the Brazilian Family Grant Program: a quasi-experimental study in the State of Rio de Janeiro. Revista Psicologia: Reflexão e Crítica, Porto Alegre, v. 25, n. 4, p. 719-729, jan. 2012.

PIRES, André. Bolsa Família e políticas públicas universalizantes: o caso de um município paulista. Cadernos de Pesquisa, Campinas, v. 38, n. 134, p. 341-366, maio/ago. 2008.

RAMOS, Marília P.; SCHABBACH, Letícia M. O estado da arte da avaliação de políticas públicas: conceituação e exemplos de avaliação no Brasil. Rev. Adm. Pública, v. 46, n. 5, p. 1271-1294, set./ out. 2012.

RASELLA, Davide et al. Effect of a conditional cash transfer programme on childhood mortality: a nationwide analysis of Brazilian municipalities. The Lancet [Online Publication], 15 may 
2013. Disponível em: <www.thelancet.com/journals/lancet/article/PIIS0140-6736(13)60715-1/ fulltext\#article_upsell>. Acesso em: 25 mar. 2014.

REIS, Elisa P. Governabilidade e solidariedade. In: VALLADARES, Lícia. Governabilidade e pobreza no Brasil. Rio de Janeiro: Civilização Brasileira, 1995. p. 49-64.

ROSINKE, João G. et al. Efeitos sociais e econômicos para o desenvolvimento local através das contribuições do Programa Bolsa Família no município de Sinop-MT no período de 2004 a 2009. Revista Interações, Campo Grande, v. 12, n. 1, p. 77-88, jan./jun. 2011.

SÁ, Maria O. L. de; SILVA, Lucimeiry B. da. Uma análise da aplicação do Programa Bolsa Família (PBF) no Município de São Bentinho - PB. In: ENAPG, 2012, Salvador. Anais... Salvador: Anpad, 2012. Disponível em: <www.anpad.org.br/evento.php?acao=trabalho\&cod_edicao_subsecao $=$ 866\&cod_evento_edicao=65\&cod_edicao_trabalho=15396>. Acesso em: 3 jun. 2013.

SEMASDH. Secretaria Municipal de Manaus de Assistência Social e Direitos Humanos. Bolsa Família Municipal Consorciada. Disponível em: < http://semasdh.manaus.am.gov.br/bolsa-familia-municipalconsorciada/>. Acesso em: 11 jun. 2013.

SILVA, Luciana M. e; JESUS, Anderson M. de. Programa Bolsa Família: uma análise do programa de transferência de renda brasileiro. Field Actions Science Reports [Online], v. Special issue 3, feb. 2011. Disponível em: <http://factsreports.revues.org/1319>. Acesso em: 17 maio 2013.

TORRES, Marcelo D. de F. Estado, democracia e administração pública no Brasil. Rio de Janeiro: FGV, 2004.

TRALDI, Daiane R. C.; ALMEIDA, Luiz M. de M. C.; FERRANTE, Vera L. S. B. Repercussões do Programa Bolsa Família no município de Araraquara, SP: um olhar sobre a segurança alimentar e nutricional dos beneficiários. Revista Interações, Campo Grande, v. 13, n. 1, p. 23-37, jan./jun. 2012.

Michelle Costa Marques dos Santos é administradora pública, especialista em administração tributária e mestranda em contabilidade e controladoria pela Universidade Federal do Amazonas (Ufam). E-mail: michelle.d.santos@caixa.gov.br.

Antonio Gouveia Junior é contador, administrador, especialista em gestão pública e mestrando em contabilidade e controladoria pela Universidade Federal do Amazonas (Ufam). E-mail: antonio.g.junior@ ibge.gov.br.

Paulo Roberto Marques de Oliveira é administrador, advogado, especialista com MBA em gestão de organizações, operações e serviços, especialista em docência do ensino superior e mestrando em contabilidade e controladoria pela Universidade Federal do Amazonas (Ufam). E-mail: oliveira.prm@gmail.com.

Daniel Reis Armond de Melo é doutor em administração pela Universidade Federal da Bahia (Ufba), professor adjunto da Universidade Federal do Amazonas (Ufam). E-mail: daniel.armond@gmail.com.

Waldemar Antonio da Rocha de Souza é doutor em ciências (economia aplicada) pela Universidade de São Paulo (USP), com pós-doutorado pela USP/Esalq, e professor adjunto da Universidade Federal do Amazonas (Ufam). E-mail: prof.wsouza@gmail.com. 